\title{
Política de assistência social e coordenação federativa no Brasil
}

Márcia Miranda Soares

Universidade Federal de Minas Gerais (UFMG)

Edite da Penha Cunha

Universidade Federal de Minas Gerais (UFMG)

O artigo analisa a política de assistência social no âmbito da organização federativa do Estado brasileiro. Para isso, apresenta e discute as transformações ocorridas na assistência social em sua configuração atual, da Constituição de 1988 até o período atual. A política de assistência social se assenta na afirmação de direito universal a ser efetivado pelo Estado, de forma integrada com outras políticas sociais e coordenada entre os entes governamentais, devendo contar com a participação da sociedade. O foco do trabalho para entender as mudanças e perspectivas atuais para a assistência social é o Estado federal, configurado por relações intergovernamentais mediadas por escassos recursos de interlocução e articulação federativa e pelo amplo papel indutor da União. É nesse contexto que se apresentam alguns desafios para o avanço da política: financiamento governamental; maior envolvimento dos estados; baixa capacidade gerencial dos municípios e o aumento da participação social.

Palavras-chave: assistência social, seguridade social, bem estar social, desigualdade social, políticas sociais, relações intergovernamentais

[Artigo recebido em 9 de novembro de 2013. Aprovado em 6 de junho de 2015] 


\section{Políticas de asistencia social y coordinación federativa en Brasil}

El artículo analiza la política de asistencia social en el ámbito de la organización federativa del Estado brasileño y debate los cambios ocurridos en esta política desde la Constitución de 1988 hasta los días actuales. La política de asistencia social brasileña se sostiene a partir de su afirmación como derecho universal a ser efectuado por el Estado, teniendo como ejes: (i) la integración con otras políticas sociales, (ii) la coordinación de los entes gubernamentales; (iii) la previsión de participación de la sociedad. El foco del artículo es el Estado brasileño y las relaciones intergubernamentales establecidas, que son mediadas por escasos recursos de interlocución y articulación federativa y, además, que son inducidas a través de la Unión. En esto contexto, se presentan algunos desafíos para el avance de la política de asistencia social: los escasos presupuestos gubernamentales; la reducida participación de los estados; la baja capacidad de gestión de los municipios y el aumento de la participación social.

Palabras clave: asistencia social, seguridad social, bienestar social, desigualdad social, políticas sociales, relaciones intergubernamentales

\section{The Social Assistance Policy and Federative Coordination in Brazil}

The article analyzes the social assistance policy in the context of federative organization of the Brazilian state. For this purpose, it presents and discusses the changes occurred in social assistance, since the 1988 Constitution to the current period. The social assistance policy is based on the assertion of a universal right to be made by the state, integrated with other social policies and coordinated between governmental entities besides the participation of society. The focus of the work to understand the changes and current perspectives on social assistance is the federal state, structured by intergovernmental relations mediated by scarce resources of federative interlocution and articulation and the widespread inductive role of the Union. That is the background to present some challenges to advance this policy: governmental funding, greater involvement of states, low management capacity of municipalities and the increase in social participation.

Keywords: social assistance, social security, social welfare, social inequality, social policy, intergovernmental relations 


\section{Introdução}

O objetivo deste artigo é apresentar e analisar a política de assistência social sob a perspectiva do federalismo brasileiro, com destaque para o período da nova ordem constitucional. O federalismo é uma variável institucional importante para o entendimento da conformação e da implementação de políticas sociais. Estudos como os de Peterson (1995), Obinger, Leibfried e Castles (2005) e Arretche (2000, 2009) apontam que o federalismo varia entre os países e ao longo do tempo e pode ser obstáculo ou favorecer as políticas sociais, dependendo de sua conformação.

O caso brasileiro é exemplar de uma dinâmica federativa que tem oscilado entre momentos de maior ou menor centralização, algo historicamente associado às alternâncias entre regime democrático e autoritário, mas também presente em suas experiências democráticas, como a atual. A configuração do federalismo tem consequências importantes sobre as políticas sociais, incluindo a assistência social, que também é marcada por transformações significativas em sua trajetória, principalmente quando são considerados o momento atual e o período que antecede os anos 1980. Contudo, poucos trabalhos buscaram apresentar e analisar a política de assistência social sob a ótica do federalismo. Este artigo busca contribuir e estimular essa reflexão.

A assistência social surgiu no mundo e se desenvolveu como ações voltadas para minimizar ou extinguir as condições precárias de vida de indivíduos em situação de pobreza, ou seja, às margens da dinâmica econômica dominante. Como tal, prevaleceu até o século 20 no âmbito das redes de solidariedade social constituídas por parentescos, vizinhança, grupos de trabalho e organizações religiosas.

A caracterização de quais sejam os indivíduos em situação de pobreza e a percepção sobre as causas e consequências de sua condição têm variado ao longo do tempo e do espaço. Atreladas a essas variações, têm-se diferentes formas de participação do Estado no provimento de assistência social, na configuração dessa como política pública e na sua passagem de ação filantrópica para direito social.

Até o século 20, a assistência social era dominada pela esfera privada, com pouca presença do Estado. Esse atuava em "caráter suplementar, para coordenar e oferecer tipos especiais de serviços" (MARSHALL, 1967, p.19). O aspecto suplementar e residual das políticas assistenciais foi enfatizado no contexto das transformações capitalistas industriais que provocaram a urbanização e o assalariamento do trabalho, distinguindo duas situações sociais: a do mundo do trabalho, com seus integrantes; e a dos marginais a esse mundo, pobres que demandavam ações de assistência social. É exemplar, nesse aspecto, a Nova Lei dos Pobres, de 1834, na Inglaterra, paradigma da política de assistência social dessa época, marcada 
por uma concepção difusa de pobres, na qual se apresentavam crianças, idosos, incapacitados físicos e mentais para o trabalho, entre outros, assistidos por ações diversas, entre elas o internamento. Os pobres assistidos eram contrastados com outros grupos, os de indigentes vadios, considerados moralmente fracos e devendo ser reprimidos pelo Estado.

O final do século 19, marcado pela progressão de uma crise no capitalismo industrial que ampliou o desemprego e a vulnerabilidade social dos trabalhadores, trouxe mudanças na percepção dos problemas sociais, da pobreza e, consequentemente, da política social. Na Inglaterra, o epicentro do capitalismo industrial e do liberalismo, os problemas associados à pobreza, ao desemprego e à superexploração do trabalho nas indústrias deixam de ser vistos como produtos de circunstâncias individuais como fraqueza moral e vadiagem e passam a ser tratados como oriundos de fatores impessoais da própria dinâmica social. "A nova situação exigia uma reavaliação dos direitos do cidadão e das obrigações do Estado para com este" (MARSHALL, 1967, p. 32). O Estado devia atuar de uma forma mais abrangente e complexa no sentido de garantir o bem-estar social da população. A Lei dos Pobres estava caduca e se fazia necessário ampliar as políticas sociais e torná-las mais adequadas a públicos específicos: crianças, idosos, doentes, desempregados, incapacitados para o trabalho, delinquentes, desabrigados, entre outros.

A emergência e desenvolvimento do Welfare State ou Estado Social no século 20, com destaque para os países mais desenvolvidos da América do Norte, da Europa Ocidental e da Oceania, avançou e consolidou ações amplas do Estado na instituição da previdência social, no provimento de serviços de educação e de saúde, na oferta de habitação e na prestação de assistência social. Tudo isso com importantes distinções de grau e perspectiva entre os países, configurando modelos mais residuais, mais meritocráticos ou mais redistributivos de políticas sociais (TITMUSS, 1974).

No Brasil, a trajetória da assistência social guarda similaridades com a trajetória mundial. As ações assistenciais se estabeleceram dentro de comunidades locais, com importante atuação da Igreja Católica e inexpressiva participação do Estado, marcadas por práticas filantrópicas e auxílios circunstanciais e imediatistas, com o objetivo de amenizar a pobreza, colocando os pobres distantes da perspectiva de garantia de direitos e de cidadania. Ao longo da história republicana, a assistência social sofreu transformações expressivas, com destaque para o período mais recente que instaurou uma nova ordem constitucional no País: democrática, federativa e voltada para a construção de um Estado de Bem-Estar social redistributivo. Essa nova ordem foi estabelecida em 1988, reformada e aperfeiçoada ao longo dos anos 1990 e primeira década dos anos 2000. 
A Constituição Federal de 1988 definiu a assistência social como direito do cidadão e dever do Estado e buscou romper com a sua trajetória de ação pontual, residual, caritativa e clientelista. Rejeitou seu status marginal dentro da categoria "políticas sociais" ao introduzir o conceito de seguridade social como "conjunto integrado de iniciativas dos poderes públicos e da sociedade destinado a assegurar os direitos relativos à saúde, à previdência e à assistência social". Ainda segundo a Constituição, a seguridade social teria como objetivos a "universalidade da cobertura e do atendimento e a uniformidade e equivalência dos benefícios e serviços às populações urbanas e rurais" (BRASIL, CF 1988, Art. 194).

Esses objetivos remetem diretamente à necessidade, dentro de um contexto federativo, de coordenação dos entes governamentais e de políticas redistributivas capazes de garantir a provisão igualitária de benefícios e serviços de assistência social a todos os cidadãos, em qualquer parte do território nacional.

No Estado federal brasileiro, a perspectiva de universalidade e de equidade na oferta de serviços de assistência social se apresenta como desafio em um país marcado pela autonomia política de entes governamentais tão díspares em sua capacidade de financiamento e de implementação de políticas sociais. Dessa forma, a coordenação federativa é condição para o sucesso da política de assistência social, algo que requer o protagonismo da União no estabelecimento de diretrizes gerais para a política, na negociação permanente com os estados e os municípios e na definição e distribuição dos recursos para financiamento da política.

A Carta Constitucional de 1988, reflexo de ampla mobilização social que a antecedeu, definiu uma nova organização federativa. Em reação ao centralismo autoritário precedente, a descentralização foi enfatizada e os municípios ganharam o status de terceiro ente federativo. As políticas sociais, destacando a de assistência social, foram estabelecidas como competência comum entre os três níveis de governo. Contudo, nos anos imediatamente seguintes à Constituição, algumas lacunas marcaram a busca por conciliar descentralização federativa e avanços sociais na nova ordem democrática brasileira (SOARES, 2012). A descentralização fiscal não foi acompanhada de mecanismos de coordenação federativa capazes de fazer avançar as políticas sociais, e o resultado foi uma "descentralização por ausências", na qual a União recuou e os estados e os municípios assumiram de forma desigual e atabalhoada as competências sociais (BERCOVICI, 2004). Nesse contexto, a política de assistência social pouco avançou.

A partir dos anos 1990, mudanças substantivas no campo do federalismo e das políticas sociais continuaram a operar e deram impulso à assistência social. Contudo, diversamente dos anos 1980, a perspectiva foi centralizada no processo de coordenação entre os entes federados. A União recentralizou recursos fiscais, 
principalmente por meio das contribuições sociais, o que possibilitou o aumento de gastos federais em políticas sociais, com destaque para a assistência social (CASTRo et al., 2008). A União, por meio do Executivo nacional, assumiu a primazia na formulação da política de assistência social e a coordenação federativa para sua implementação. Por um lado, passou a induzir comportamentos subnacionais por meio de legislação nacional e transferências financeiras via fundos especiais. Por outro lado, instituiu políticas de transferência direta de recursos de natureza assistencial aos cidadãos, o Benefício de Prestação Continuada (BPC) ${ }^{1}$ e o Programa Bolsa Família $(\mathrm{PBF})^{2}$. O BPC é altamente centralizado, sendo formulado no âmbito nacional e "operado por uma autarquia federal - o Instituto Nacional de Seguro Social (INSS), sem intermediação dos estados e municípios." (LICIO, 2012, p. 26). O Bolsa Família também tem suas decisões predominantemente tomadas no nível central, mas conta com a participação dos estados e os municípios na sua implementação, funcionando esses quase como "agentes administrativos do governo central" (ALMEIDA, 2005).

As mudanças operadas na concepção, no modelo de gestão e no financiamento da assistência social, na Constituição de 1988 e na legislação infraconstitucional, e sua evolução institucional como política pública nos anos 1990 e 2000 trouxeram resultados positivos para a sociedade, que passa a ter o direito legal de acesso a serviços e benefícios de assistência social. Contudo, vale reconhecer os desafios para a efetivação de sua gestão em um Sistema Único de Assistência Social (Suas). Parte dos desafios enfrentados está relacionada à dinâmica federativa. Não há um sistema estável de financiamento público da assistência social pela União, Estados e Municípios. Os estados, em sua maioria, têm avançado pouco no cumprimento de suas atribuições legais, o que inclui a execução de serviços regionalizados da proteção especial de média e alta complexidade, o cofinanciamento dos serviços, programas, projetos e benefícios eventuais e a coordenação dos municípios para o aprimoramento da gestão. A capacidade gerencial dos municípios, principais executores da política, é baixa, em um país marcado por tantas desigualdades e

\footnotetext{
${ }^{1}$ O Benefício de Prestação Continuada (BPC) visa garantir a segurança de renda, por meio de provimentos monetários, às pessoas de qualquer idade com deficiência e às pessoas idosas (com mais de 65 anos). 0 benefício está previsto na Constituição Federal de 1988, Lei Orgânica da Assistência Social (Loas) e no Estatuto do Idoso e consiste em um salário mínimo mensal repassado diretamente ao beneficiário por meio do Instituto Nacional de Seguro Social (INSS). Para ser contemplado, é preciso que o indivíduo comprove renda familiar mensal, per capita, inferior a $1 \frac{1}{4}$ do salário mínimo.

${ }^{2}$ O Programa Bolsa Família (PBF) se caracteriza pela transferência direta de renda a famílias em situação de pobreza, condicionada à presença das crianças na escola, à manutenção em dia das cadernetas de vacinação, entre outras condicionalidades.
} 
com perfil predominante de municípios pouco populosos e pobres. O caráter deliberativo da política é outro ponto a avançar, no sentido de ampliar a participação dos entes subnacionais e da sociedade na formulação e implementação da política de assistência social.

Para desenvolver e analisar a política de assistência social brasileira no contexto do federalismo atual, o artigo está organizado em três seções que abordam as interações entre os entes federados, destacando a coordenação exercida pela União. Sob essa perspectiva, a análise recai sobre os atores governamentais, e não será explorada a atuação de outros atores sociais e políticos relevantes para o processo de institucionalização dessa política. A primeira seção apresenta os precedentes da política de assistência social na Federação brasileira até o processo de redemocratização e refederalização do País nos anos 1980. Na sequência, analisa a conformação e a trajetória da política na dinâmica federativa estabelecida na nova ordem constituição, nos anos 1990 e na primeira década dos anos 2000. A segunda seção apresenta alguns avanços conquistados e discute os desafios que ainda persistem para o alcance de uma assistência social universal, promotora de bem-estar social, coordenada federativamente e gerida de forma participativa. $\mathrm{O}$ artigo termina com algumas considerações finais que sintetizam os achados e aponta novas perspectivas de estudos para o tema.

\section{A política de assistência social na Federação brasileira: da filantropia ao Sistema Único de Assistência Social - Suas (1889-2010)}

\section{Precedentes da assistência social na República Federativa Brasileira (1989-1985)}

A ação do Estado na área da assistência social na história republicana brasileira é de crescente envolvimento. Partiu-se de uma posição de alheamento na República Velha, primeiros 30 anos do último século, na qual a iniciativa de assistir aos pobres era assumida por grupos que atuavam motivados por solidariedade e compaixão. Os anos 1930 inauguraram um período de transformações econômicas e sociais que impulsionaram as políticas sociais para um novo patamar de atuação pública. 0 Estado assume competências importantes na área social, mas sob uma perspectiva predominantemente voltada para os trabalhadores urbanos inseridos no mercado formal de trabalho, com atuação residual sobre os grupos menos favorecidos e marginais ao processo de desenvolvimento capitalista.

O modelo de Estado social que emerge nos anos 1930 é meritocrático, particularista, clientelista e centralizado na União (MEDEIROS, 2001).

A assistência social é parte desse modelo, persistindo como ação de domínio de entidades privadas locais, que passam a contar com algum apoio da União em 
uma lógica marcadamente privatista e clientelista. Nos dois períodos subsequentes, a democracia de 1946 a 1964 e, principalmente, no Regime Militar de 1964 a 1985, a assistência social caminha em uma dinâmica altamente concentradora de poder no Executivo nacional e nas entidades e organizações prestadoras de ações assistenciais, com pouca participação dos estados e municípios.

O processo de redemocratização do País nos anos 1980 traz à cena demandas claras de ruptura com o padrão vigente de assistência social. O novo modelo de Estado social desenhado na Constituição de 1988, incluso nesse a assistência social, deveria ser erigido sobre os princípios da universalidade, do redistributivismo (combate às desigualdades sociais), da descentralização federativa e da participação social.

O Quadro 1 apresenta uma síntese das principais características da assistência social ao longo de sua trajetória na Federação brasileira.

\section{Quadro 1 - A assistência social no Brasil republicano (1889 a 2010)}

\begin{tabular}{|c|c|c|c|}
\hline Períodos & $\begin{array}{l}\text { Provedor } \\
\text { principal }\end{array}$ & Financiamento & Competência Federativa \\
\hline $\begin{array}{l}\text { Primeira } \\
\text { República } \\
\text { (1889-1930) }\end{array}$ & $\begin{array}{l}\text { Instituições } \\
\text { assistenciais, } \\
\text { filantrópicas e } \\
\text { religiosas. }\end{array}$ & $\begin{array}{l}\text { Predominantemente } \\
\text { privado, com auxílios } \\
\text { eventuais de órgãos } \\
\text { públicos para instituições de } \\
\text { internação como as Santas } \\
\text { Casas. }\end{array}$ & $\begin{array}{l}\text { União apoia financeiramente } \\
\text { as entidades privadas, há } \\
\text { pouca atuação dos governos } \\
\text { subnacionais e ausência de } \\
\text { coordenação federativa. }\end{array}$ \\
\hline $\begin{array}{l}\text { Era Vargas } \\
(1930-1945)\end{array}$ & $\begin{array}{l}\text { Instituições } \\
\text { sociais e } \\
\text { filantrópicas. }\end{array}$ & $\begin{array}{l}\text { Predominantemente } \\
\text { privado, com participação } \\
\text { financeira do Estado por } \\
\text { meio de subsídios públicos e } \\
\text { isenções fiscais às entidades } \\
\text { sociais filantrópicas. }\end{array}$ & $\begin{array}{l}\text { União centraliza a normatização } \\
\text { da assistência com a criação do } \\
\text { Conselho Nacional de Serviço } \\
\text { Social (CNSS) e organiza a sua } \\
\text { intervenção por meio da Legião } \\
\text { Brasileira de Assistência (LBA). }\end{array}$ \\
\hline $\begin{array}{l}\text { República } \\
\text { Nova } \\
(1946-1964)\end{array}$ & $\begin{array}{l}\text { Instituições } \\
\text { sociais e } \\
\text { filantrópicas. }\end{array}$ & $\begin{array}{l}\text { Predominantemente } \\
\text { privado, com apoio da União } \\
\text { por meio de subsídios, } \\
\text { isenções fiscais e convênios } \\
\text { celebrados com entidades } \\
\text { filantrópicas. }\end{array}$ & $\begin{array}{l}\text { Manutenção do padrão } \\
\text { anterior, menos centralizado, } \\
\text { mas ainda descoordenado e } \\
\text { sem afirmar a responsabilidade } \\
\text { pública. }\end{array}$ \\
\hline $\begin{array}{l}\text { Ditadura } \\
\text { Militar } \\
\text { (1964-1985) }\end{array}$ & $\begin{array}{l}\text { Instituições } \\
\text { sociais e } \\
\text { filantrópicas. }\end{array}$ & $\begin{array}{l}\text { Maior participação do } \\
\text { Estado via criação de } \\
\text { benefícios individuais da } \\
\text { União e conveniamento } \\
\text { com instituições públicas e } \\
\text { privadas. }\end{array}$ & $\begin{array}{l}\text { União expande a oferta de } \\
\text { ações assistenciais, diretamente } \\
\text { e via convênios com estados, } \\
\text { municípios e entidades } \\
\text { privadas. Centralização e baixa } \\
\text { articulação com as ações } \\
\text { assistências subnacionais. }\end{array}$ \\
\hline
\end{tabular}




\begin{tabular}{|l|l|l|l|}
\hline Períodos & $\begin{array}{l}\text { Provedor } \\
\text { principal }\end{array}$ & Financiamento & Competência Federativa \\
\hline $\begin{array}{l}\text { Nova } \\
\text { República } \\
(1985-\end{array}$ & $\begin{array}{l}\text { Estado, em } \\
\text { parceria com } \\
\text { a sociedade } \\
\text { civil. }\end{array}$ & $\begin{array}{l}\text { Estatal e privado, com } \\
\text { ampliação significativa } \\
\text { de aporte de recursos } \\
\text { públicos para benefícios e } \\
\text { programas de transferência } \\
\text { de renda, além de serviços } \\
\text { socioassistenciais }\end{array}$ & $\begin{array}{l}\text { União formula as normas } \\
\text { gerais da política e coordena } \\
\text { a implementação das ações } \\
\text { assistenciais pelos municípios, } \\
\text { com baixa cooperação dos } \\
\text { estados. }\end{array}$ \\
\hline
\end{tabular}

Fonte: Elaboração própria.

\section{A assistência social na nova ordem constitucional}

A transição do regime autoritário para a democracia trouxe para o País reivindicações de autonomia subnacional e de maior justiça social. Esses anseios se estruturam na ordem constitucional de 1988 por meio de um novo pacto federativo e pela expansão dos direitos sociais. O novo pacto promoveu um amplo processo de descentralização territorial. Estados e municípios reconquistaram a autonomia política para instituir seus governos de forma independente do poder central. Os municípios ganharam o status constitucional de terceiro ente federativo. A descentralização fiscal aumentou a participação dos estados e, principalmente, dos municípios na distribuição das receitas públicas. Na busca por mais igualdade social, a constituição cidadã ampliou consideravelmente os direitos sociais.

No que concerne à assistência social, a evolução de formas assistenciais privadas, alicerçadas na sociedade civil, para formas institucionais e públicas de seguridade social, conforme Cunha (2013), contou com a articulação de representantes da policy community da assistência social ${ }^{4}$ junto a parlamentares constituintes, o que assegurou a inscrição da assistência social na Constituição de 1988 como direito do cidadão, garantido a quem dela necessitar. A contribuição deixaria de ser um impedimento à universalização e à equidade no acesso aos serviços assistenciais (CF/1988, art. 203).

\footnotetext{
${ }^{3}$ Os serviços socioassistenciais de proteção social básica e proteção social especial no Suas são organizados em: vigilância social, proteção social e defesa social e institucional.

${ }^{4}$ A policy community da assistência social constituía-se, no processo constituinte, de membros da academia, que ofereceram subsídios conceituais para as mudanças que se pretendia; de organizações de classe, principalmente as de assistentes sociais, que mobilizaram os profissionais da área; de organizações não governamentais prestadoras de serviços, que trouxeram ao debate as questões relacionadas ao cotidiano de suas ações; e de associações representantes dos segmentos tradicionalmente atendidos pela assistência social, que buscavam a melhoria nos patamares de atendimento.
} 
Estabeleceu-se para as políticas sociais o rompimento da lógica dual que prevaleceu nos períodos anteriores:

o setor privado para os ricos, os planos de saúde para um grupo seleto de assalariados e classes médias, os serviços públicos para pagantes da previdência e, para os pobres, a caridade feita, em geral, por entidades municipais privadas sem fins lucrativos ou filantrópicas com apoio estatal (FALEIROS, 2000, p. 48).

Os princípios da universalidade, da equidade, da descentralização e da participação social foram estabelecidos como norteadores das políticas sociais. A integração dessas políticas também se tornou uma diretriz consubstanciada no estabelecimento do sistema de seguridade social: "um conjunto integrado de ações de iniciativa dos Poderes Públicos e da sociedade, destinadas a assegurar os direitos relativos à saúde, à previdência e à assistência social" (CF/1988, art. 194).

Em um país marcado por enormes desigualdades sociais, as políticas sociais foram estabelecidas como competências comuns da União, dos Estados, do Distrito Federal e dos Municípios. As normas para cooperação entre os entes federados na promoção das políticas foram remetidas à legislação infraconstitucional, a ser elaborada com a superveniência da legislação federal e o caráter suplementar da legislação subnacional (CF/1988, art. 24 e 25).

A partir dos anos 1990, o Estado brasileiro se defronta com a tarefa de implementar a Constituição de 1988, e novas regulamentações e definições foram necessárias para fazer avançar as políticas sociais, como um todo, e a política de assistência social, em específico. O novo contexto federativo, marcado por autonomia política e descentralização de recursos financeiros aos estados e municípios, trazia desafios adicionais. Como se articulariam e atuariam União, Estados e Municípios na formulação e implementação das políticas de assistência social? Quem financiaria a expansão dessas políticas? Em que consistiria a descentralização políticoadministrativa preconizada no texto constitucional? E como garantir a "participação da população, por meio de organizações representativas, na formulação das políticas e no controle das ações em todos os níveis" (CF/1988, art. 204)?

A partir de iniciativas e articulações da policy community da assistência social, ocorreu a aprovação da Lei no 8.742, de 1993, a Lei Orgânica da Assistência Social (Loas). A política de assistência social ganhou contornos mais nítidos com a Loas. A lei definiu a gestão da política em um sistema único nacional, descentralizado e participativo, integrado pelos entes federativos, pelas respectivas instâncias deliberativas de assistência social e pelas entidades e organizações de assistência social. Para viabilizar esse sistema, estabeleceu o planejamento e o financiamento como responsabilidade comum dos entes federados. O financiamento da política ocorreria com os recursos da União, dos 
Estados, dos Municípios, com destaque para as contribuições sociais previstas no art. 195 da Constituição Federal. Os recursos dos entes deveriam ser alocados nos fundos especiais estabelecidos em cada instância de governo: Fundo Nacional de Assistência Social (FNAS); Fundos Estaduais de Assistência Social (Feas) e Fundos Municipais de Assistência Social (FMAS). Cada fundo seria formado a partir de recursos próprios e, para os entes subnacionais, por repasses intergovernamentais do FNAS, e no caso dos municípios, também do Feas. Na sistêmica de transferências de recursos fundo a fundo, condicionaram-se os repasses da União aos entes subnacionais à elaboração do Plano de Assistência Social e ao efetivo funcionamento do Conselho de Assistência Social e do Fundo de Assistência Social. Os conselhos de assistência social foram definidos como as instâncias participativas e deliberativas do sistema, conjuntamente com as conferências de assistência social, fórum ampliado de participação.

A Loas instituiu um novo ordenamento institucional para as relações intergovernamentais na área da assistência social. A União assumiu o papel de principal formuladora, financiadora e coordenadora da política, induzindo estados e municípios, via regulamentação e repasse de recursos financeiros, a adotarem o novo modelo de gestão. Dessa forma, tem-se uma formulação centralizada da política, dado que o Governo Federal define as diretrizes gerais e controla a distribuição de recursos financeiros mediante a adesão aos seus programas, o que restringe a autonomia dos governos subnacionais (ARRETCHE, 2000, p. 2007). Contudo, não há dúvida quanto ao papel de destaque que os municípios assumem na execução da política de assistência social, o que significa uma descentralização administrativa que, em certa medida, Ihes possibilita também intervir na definição da política. Tudo isso aponta para uma dinâmica federativa centralizada para a política de assistência social. Mas se trata de uma centralização democrática, com o protagonismo do Poder Executivo nacional, que requer a aprovação de suas iniciativas no Legislativo nacional, que induz e não impõe regras e que abre canais para a participação dos entes subnacionais e da sociedade civil nas tomadas de decisão.

\section{A assistência social no Governo Fernando Henrique Cardoso (1995- 2002)}

O processo de formulação da política de assistência social avança nos anos 1990 com regulamentações complementares para disciplinar os procedimentos operacionais em cada nível de governo.

O primeiro mandato do Governo FHC extinguiu as estruturas burocráticas federais responsáveis pela assistência social e criou a Secretaria de Assistência Social (SAS), em 1995. Esse órgão, vinculado ao Ministério da Previdência e Assistência Social (MPAS), impulsionou a aprovação da primeira Norma Operacional Básica da Assistência Social (NOB), por meio da Resolução do Conselho Nacional de Assistência Social (CNAS) no 204, de 1997. Essa norma visava disciplinar o processo 
de descentralização político-administrativo nas três esferas de governo. Nomeou as competências dos entes federados, definiu os níveis de gestão, a operacionalização e a sistemática de financiamento das ações socioassistenciais, assim como os critérios de partilha e prestação de contas dos recursos. Também criou a Comissão Intergestores Tripartite - CIT (nacional) ${ }^{5}$ e as Comissões Intergestores Bipartite - CIB (estadual) ${ }^{6}$, com caráter consultivo e a atribuição de discutir e pactuar aspectos relacionados à gestão da política.

Em 1998, foi aprovada a Política Nacional de Assistência Social e a Norma Operacional Básica da Assistência Social (Resolução CNAS no 207, de 1998), que foi republicada em 1999. A NOB 1999 definiu os critérios e os mecanismos para a transferência de recursos do Fundo Nacional de Assistência Social para os fundos de assistência social estaduais e municipais e o papel e as atribuições dos conselhos quanto ao controle dos fundos e à execução dos planos de assistência social. Definiu, também, as atribuições das comissões intergestores como instâncias de negociação e pactuação, que passaram a ter caráter deliberativo na gestão da política.

Em 1995, paralelamente a esse processo de institucionalização da política de assistência social, o Governo Federal criou o Programa Comunidade Solidária, presidido pela primeira dama e vinculado à Presidência da República. O programa, cujo propósito era o combate a situações de extrema pobreza, estava alinhado ao modelo de reforma administrativa da época e enfatizou a participação do terceiro setor no provimento de serviços sociais (SILVA, 1999). Essa perspectiva privada na oferta dos serviços de assistência social constituiu-se em um revés na afirmação da responsabilidade do poder público pela prestação de assistência social a todos os necessitados. Assim, apesar dos avanços na institucionalização da política de assistência social,

[...] ao longo dos anos noventa, a prestação dos serviços assistenciais sofreria poucas mudanças em seu modo de operação. As entidades privadas sem fins lucrativos, financiadas por transferências governamentais e isenções fiscais, permanecem como principais provedoras dos serviços, atuando em um contexto de baixa regulação e coordenação estatal (VAITSMAN et al., 2009, p. 734).

\footnotetext{
5 A CIT é composta por representantes da União, indicados pelo órgão gestor federal da política de assistência social; representantes dos estados, indicados pelo Fórum Nacional de Secretários Estaduais de Assistência Social (Fonseas); e representantes dos municípios, indicados pelo Colegiado Nacional de Gestores Municipais de Assistência Social (Congemas).

${ }^{6}$ As CIB são compostas por representantes do estado, indicados pelo órgão gestor estadual da assistência social, e por representantes dos municípios, indicados pelo Colegiado Estadual de Gestores Municipais de Assistência Social (Coegemas).
} 
A década de 2000 inaugurou uma nova vertente de políticas federais no campo da assistência social: as políticas de transferência de renda. No âmbito federal, os programas de transferência de renda tiveram início em 2001, com a criação do Bolsa Escola, e do Programa Nacional de Renda Mínima vinculado à saúde, conhecido como Bolsa Alimentação. Em 2002 nasceu o Auxílio-Gás, vinculado ao Ministério das Minas e Energia. (CARDoso; JACCOUd, 2005, p. 221).

No final do Governo Fernando Henrique Cardoso, verificam-se três frentes desarticuladas de atuação do Governo Federal na área de assistência social: os programas de transferência de renda espalhados por diferentes ministérios, as ações do Programa Comunidade Solidária e as tentativas de implementação da Loas no MPAS. A necessidade da unificação dos programas de transferência de renda é colocada a partir de um diagnóstico sobre os programas sociais em desenvolvimento no País, elaborado na transição do Governo FHC para o Governo Lula (YAZBEK, 2012). Inicia-se, então, ao final desse governo, um movimento de unificação das transferências, que só será concluído no governo seguinte.

\section{A assistência social no Governo Lula (2003-2010)}

O Governo Lula conformou uma nova institucionalização para as políticas de assistência social, avançou na coordenação federativa e ampliou os programas de transferência direta de renda. Em 2003, foi criado o Programa Bolsa Família, unificando os programas de transferência de renda do governo anterior.

Em 2004, a criação do Ministério de Desenvolvimento Social (MDS), "que unificou a política de combate à fome com as políticas de transferência de renda e de assistência social, foi um passo significativo na direção de articular um conjunto de iniciativas na perspectiva do enfrentamento à pobreza no país" (YAZBEK, 2012, p. 308). O MDS, desde então, passa a ser um ator relevante na formulação da política de assistência social, tendo destaque as transferências diretas de renda, mas também a nova agenda política de implantação e consolidação do Sistema Único de Assistência Social (Suas), inspirado na experiência do Sistema Único de Saúde (SUS).

O Suas foi deliberado, em 2003, na IV Conferência Nacional de Assistência Social e instituído pela nova Política Nacional de Assistência Social (PNAS/2004). O objetivo é avançar na consolidação de um sistema nacional de assistência social, articulando e integrando ações dos diferentes entes da federação e das entidades privadas, o que envolve maior coordenação federativa.

A aprovação da PNAS/2004 abriu uma nova fase de institucionalização da assistência social ao definir os conceitos e os parâmetros para a organização do Suas, segundo diretrizes de territorialização do planejamento, de responsabilização estatal pela garantia da proteção social, de centralidade das ações na família e de 
profissionalização dos recursos humanos. Definiu com maior precisão a divisão de competências administrativas entre os entes federados e entre o setor público e privado ao estabelecer a concepção de rede socioassistencial. A oferta de proteção social básica estaria a cargo dos poderes executivos municipais, responsáveis pela implantação de unidades públicas estatais de assistência social, os Centros de Referência da Assistência Social (Cras) ${ }^{7}$. A proteção especial de média complexidade seria tarefa dos poderes executivos municipais e estaduais, por meio dos Centros de Referência Especializados de Assistência Social (Creas) ${ }^{8}$. A proteção especial de alta complexidade ${ }^{9}$ seria estruturada por municípios de médio e grande porte, bem como pela esfera estadual, em parceria com as entidades sem fins lucrativos.

A Norma Operacional Básica de 2005 (NOB/Suas), instrumento de regulação dos conteúdos e definições da PNAS/2004 que orientam o funcionamento do Suas, estabeleceu as bases para a operacionalização da gestão descentralizada do sistema, instituindo os níveis de gestão municipal - inicial, básica e plena - e o Pacto de Aprimoramento da Gestão Estadual, celebrado entre o gestor federal e o gestor estadual e do Distrito Federal para o estabelecimento de objetivos e metas para os níveis estaduais.

Outra novidade foi o Índice de Gestão Descentralizada (IGD), criado em 2006, visando ao incentivo financeiro aos municípios que cumprem certas metas de aprimoramento da gestão do Programa Bolsa Família, relacionadas à atualização do Cadastro Único para Programas Sociais (CadÚnico) ${ }^{10}$ e ao acompanhamento das condicionalidades. O mesmo índice foi estendido aos estados, em 2010, para que esses fornecessem apoio técnico operacional a seus municípios no aperfeiçoamento

\footnotetext{
7 "Cras é a unidade pública estatal de base territorial, localizada em áreas com maiores índices de vulnerabilidade e risco social, que abrange um total de até 1.000 famílias/ano. Executa serviços de proteção social básica às famílias, organiza e coordena a rede de serviços socioassistenciais locais da política de assistência social" (PNAS, 2004, p. 35).

${ }^{8} \mathrm{O}$ Creas é a unidade pública estatal de abrangência municipal, estadual ou regional, destinada à prestação de serviços a indivíduos e famílias que se encontram em situação de risco pessoal ou social, por violação de direitos ou contingência. Suas ações objetivam o atendimento às famílias e indivíduos com seus direitos violados, mas cujos vínculos familiar e comunitário não foram rompidos.

${ }^{9}$ As ações de proteção especial de alta complexidade "garantem proteção integral - moradia, alimentação, higienização e trabalho protegido para famílias e indivíduos que se encontram sem referência e/ou em situação de ameaça, necessitando ser retirados de seu núcleo familiar e/ou comunitário". São exemplos de "equipamentos" de proteção especial de alta complexidade os abrigos, os albergues e as casas de passagem.

${ }^{10}$ O Cadúnico, regulamentado pelo Decreto no 6.135/2007, identifica e caracteriza as famílias com renda mensal de até meio salário mínimo por pessoa ou de três salários mínimos no total. É utilizado para identificar os beneficiários dos programas sociais do Governo Federal (BRASIL, 2007). A obrigatoriedade de cadastro dos possíveis beneficiários e a seleção dos mesmos a partir do Cadúnico possibilita melhor integração, focalização, monitoramento e controle dos programas sociais.
} 
do programa. O índice busca fortalecer a gestão pública municipal e estadual na implementação do Bolsa Família.

A necessidade de profissionalização da política de assistência social, com vistas a garantir a qualidade dos serviços aos usuários do Suas, levou, em 2007, à aprovação pelo CNAS da Norma Operacional Básica de Recursos Humanos do Suas (NOB/RH). A norma surgiu a partir da constatação de que os trabalhadores envolvidos na prestação de serviços socioassistenciais são essenciais para o avanço e consolidação do Suas. Essa norma reconhece a importância da qualificação e valorização dos trabalhadores atuantes no Suas para garantir aos usuários serviços públicos de qualidade.

Em 2009, estabeleceram-se as bases de padronização nacional dos serviços do Suas por meio da Tipificação de Serviços Socioassistenciais ${ }^{11}$, que se constitui em uma padronização dos serviços (nomenclatura, descrição, usuários, objetivos, provisões, aquisições dos usuários, condições e formas de acesso, unidade, período de funcionamento, abrangência, articulação em rede e impacto social esperado), organizados por níveis de complexidades das proteções.

\section{Avanços e desafios da política de assistência social na Federação brasileira}

\section{Avanços na política de assistência social}

Nogeral, pode-se afirmar que foram positivas as mudanças operadas na assistência social no contexto da Federação brasileira desde os anos 1980. A situação anterior era de governos nacional e subnacionais atuando de forma desarticulada e como subsidiários da ação privada na oferta de assistência social. A União centralizava e definia unilateralmente as diretrizes e ações da política, de forma autoritária e clientelista. Estados e municípios tinham participação marginal na promoção da assistência social, reproduziam os padrões autoritários e clientelistas do plano nacional e atuavam de forma fragmentada e descoordenada federativamente e junto às entidades privadas. Na atualidade, há uma configuração diversa da política de assistência social, com destaque para as relações intergovernamentais. A União assumiu a tarefa de formular a política e coordenar sua implementação, com a participação dos entes subnacionais e da sociedade civil organizada. Sob essa perspectiva, podem-se assinalar como avanços na política pública:

\footnotetext{
${ }^{11}$ A Tipificação foi instituída por meio da Resolução no 109, de 2009, do Conselho Nacional de Assistência Social, tendo sido previamente pactuada na Comissão Intergestores Tripartite (CIT).
} 
1) O financiamento governamental avançou ao consolidar o repasse dos benefícios monetários da assistência social diretamente aos cidadãos ou às famílias, bem como o custeio dos serviços socioassistenciais por meio das transferências fundo a fundo.

A transferência direta de renda do Governo Federal aos cidadãos elimina intermediários, diminui custos e aumenta a transparência na definição e aplicação dos recursos. Dessa forma, o Benefício de Prestação Continuada e o Bolsa Família têm sido efetivos na diminuição da pobreza e das desigualdades sociais no País. Vale assinalar que, enquanto o BPC é operado exclusivamente pela União, os municípios e, em menor escala, os estados participam do PBF e recebem incentivos financeiros para cooperarem com a União em sua implementação.

A modalidade de transferência fundo a fundo, diferente dos convênios, possibilita maior regularidade de recursos orçamentários para a assistência social e repasses automáticos e permanentes da União para os níveis estadual e local, diminuindo o espaço das barganhas políticas. Também proporciona maior transparência e efetividade aos gastos ao definir condições e critérios para os repasses da União aos entes subnacionais e privados. Como condições para receber os recursos, estados e municípios devem garantir aportes de recursos próprios orçamentários para a área, fazer o planejamento da política em seu âmbito e assegurar o funcionamento dos conselhos de assistência social. A transferência dos recursos do FNAS para os fundos subnacionais adota como critérios pisos de proteção social definidos por nível de complexidade dos serviços prestados, exigindo o cofinanciamento dos entes subnacionais.

2) Planejamento governamental: o CNAS, através da Resolução no 182, de 1999, estabeleceu que os planos de assistência social devem definir todos os programas, projetos, benefícios e serviços de assistência social, por um período de quatro anos, tendo vigência no segundo ano da gestão governamental em que forem elaborados e terminando no primeiro ano da gestão subsequente. Esse período é o mesmo do Plano Plurianual de Ação Governamental (PPAG), e o intuito é a articulação entre o planejamento orçamentário do ente federado e da política de assistência social no médio prazo.

A perspectiva de ações socioassistenciais definidas para um período de médio prazo, com objetivos e metas, significou um avanço para uma política marcada pela fragmentação, descontinuidade e ineficiência. E isso vale para União, Estados e Municípios, dado que o planejamento é condicionante para recebimento de recursos do Fundo Nacional de Assistência Social e possibilita maior previsibilidade, continuidade e coordenação das ações. 
3) Perspectiva sistêmica na prestação de serviços: a conformação de uma rede socioassistencial que busca coordenar as ações dos entes federados e das entidades socioassistenciais privadas na oferta de serviços representou um avanço significativo. Analisando a disponibilização nos municípios de estruturas permanentes de assistência social, a Pesquisa de Informações Básicas Municipais (INSTITUTO BRASILEIRO DE GEOGRAFIA E ESTATísticA, 2009), do IBGE, apontou que quase todos os municípios $(99,9 \%)$ declararam possuir, em 2009, estrutura organizacional para tratar da política de assistência social. A oferta de serviços socioassistenciais alcançou ampla disseminação, demonstrada pelos altos percentuais de municípios que disseram oferecer serviços de proteção social básica $(97,9 \%)$ e de proteção social especial $(87,6 \%)$.

A Tipificação Nacional dos Serviços Socioassistenciais possibilita a estruturação de uma rede de serviços compartilhada por unidades estatais e entidades privadas, a elaboração de indicadores de qualidade para o Suas, em relação ao padrão mínimo estabelecido, e a explicitação para a população sobre o que pode ser exigido em termos de atendimento na política (INSTITUTO DE PESQUISA ECONÔMICA APLICADA, 2011).

Como nos alerta Arretche (2010), ainda que os entes subnacionais tenham relativa autonomia decisória no planejamento regional e local, no dimensionamento dos serviços a serem ofertados e na definição do montante de recursos orçamentários próprios alocados nos seus orçamentos, "a regulação federal parece ser uma condição para 'amarrar' subunidades independentes em torno de um dado objetivo nacional" (ARRETCHE, 2010, p. 611). Isso é relevante na assistência social, cujos serviços edificaram-se sob uma rede privada filantrópica, distante da responsabilização direta do Estado pela oferta dos serviços socioassistenciais.

4) Coordenação federativa: a coordenação federativa na área de assistência social foi assumida pela União nos anos 1990 e essa tem atuado de forma abrangente, induzindo comportamentos subnacionais via regulamentações e transferências de recursos. Cabe também destacar a criação das comissões intergestores - CIB e CIT -, importantes canais de interlocução e negociação federativa, sob a inspiração da CIB e CIT existentes no âmbito da política de saúde. As comissões intergestores constituem fóruns permanentes de gestão colegiada que deliberam sobre os aspectos operacionais da implementação do Suas, possibilitando a participação dos executivos estaduais e municipais na definição da política nacional de assistência social. Esses fóruns são importantes principalmente para os municípios, que ganharam o status federativo na Constituição Federal de 1988 e desempenham importante papel na execução das políticas sociais. Contudo, ficaram alijados de 
representação no plano político nacional, diferente dos estados, que têm no Senado a casa de representação de seus interesses.

Esses canais podem atuar positivamente em duas direções, minimizando a centralidade da União na formulação da política de assistência social e o que Abrucio (2005) denominou de "federalismo compartimentalizado", em que prevalece uma ação estanque de cada esfera governamental na gestão das políticas públicas, com poucos incentivos para a parceria e o entrelaçamento entre as unidades federativas.

5) Canais de participação e deliberação: os conselhos e conferências de políticas públicas são canais importantes de participação e deliberação da sociedade civil na política de assistência social, e suas expansões e fortalecimento guardam relação com o processo de normatização da política no Governo Federal. É exemplar o estudo realizado por Côrtes sobre a experiência dos conselhos de políticas públicas na Região Metropolitana de Porto Alegre, entre 1990 e 2002. A autora observou que "a maioria dos conselhos de assistência social - 67,7\%, 21 em 31 - constituiuse entre 1995 e 1996, quando foram estabelecidas as normas de descentralização que condicionavam o repasse de recursos à sua criação" (CôRTES, 2005, p.162). A participação da sociedade civil na formulação, implementação e controle da política é fundamental para o alcance dos resultados almejados, constituindo-se como um importante avanço a expansão dos conselhos e conferências de assistência social nos três níveis de governo. É exemplar a criação do Suas a partir de deliberação da IV Conferência Nacional de Assistência Social (2003), precedida de ampla mobilização social por meio de conferências municipais e estaduais.

\section{Desafios à política de assistência social}

Destacados alguns avanços, cabe indagar sobre os desafios apresentados à política de assistência social. O objetivo é refletir sobre aspectos que podem consolidar as conquistas e promover as mudanças no sentido de uma política universal, equitativa, descentralizada e participativa. Nessa perspectiva, as relações intergovernamentais são cruciais e alguns pontos merecem consideração:

1) Financiamento governamental: apesar dos avanços, algumas questões relacionadas ao financiamento da assistência social geram incertezas quanto ao futuro da política. A principal diz respeito à indefinição de recursos a serem comprometidos com a política. Diferente da saúde e da educação, a assistência não tem assegurados constitucionalmente percentuais mínimos das receitas nacionais, estaduais ou municipais para seu financiamento. Isso coloca a gestão da assistência social à mercê da decisão de cada nível de governo quanto ao montante de recursos próprios para o seu financiamento e intensifica os esforços do Governo Federal na instituição de mecanismos que comprometam os entes 
subnacionais no cofinanciamento, em especial os governos estaduais que têm demonstrado um envolvimento relativamente menor no financiamento do Suas (INSTITUTO DE PESQUISA ECONÔMICA APLICADA, 2012). É verdade que a vinculação excessiva de receitas governamentais não é desejável porque enrijece a gestão pública, tornando-a menos capaz de responder às demandas e especificidades regionais e locais. Mas, em um contexto em que a vinculação já é excessiva, ficar fora da "repartição constitucional das receitas" significa maior vulnerabilidade da política de assistência social a cortes orçamentários, em decorrência de mudanças econômicas ou políticas.

Outro desafio no financiamento da assistência social é a instituição dos critérios de transferência de recursos federais para o custeio dos serviços nos níveis subnacionais por meio de pisos. A adoção dos pisos vincula recursos a determinados serviços e, com isso, diminui a autonomia municipal para definir uma rede de serviços mais condizente com a realidade local. É defensável a busca por um conjunto de serviços essenciais prestados em todo o território nacional, o que envolve também a garantia de um piso financeiro a todos os municípios. Contudo, o significado desse padrão mínimo, a forma de viabilizá-lo e o nível de autonomia subnacional devem ser objeto de contínuo debate e pactuação nos fóruns de deliberação.

2) Dualidade no Suas: enquanto a gestão dos serviços socioassistenciais ocorre de modo mais descentralizado e compartilhado entre a União, Estados e Municípios, programas de transferência direta de renda como o Bolsa Família e o Benefício de Prestação Continuada, que concentram os recursos públicos direcionados à política de assistência social, permanecem centralizados no Governo Federal. O PBF tem a formulação centralizada (ALMEIDA, 2005; BICHIR, 2011; LICIO, 2012), sendo que estados e municípios atuam apenas na execução. Aos estados cabe a participação na gestão do PBF, com a função de apoiar os municípios com suporte tecnológico e capacitação. Os municípios atuam em especial na alimentação do cadastro e no acompanhamento das famílias quanto ao cumprimento das condicionalidades do programa (Cadúnico). O BPC é mais centralizado que o Bolsa Família, uma vez que não há participação dos estados e municípios na sua formulação e execução. 0 cadastro e a concessão desse benefício são realizados pelo Governo Federal, via INSS, sem a intermediação dos estados e municípios.

Como analisado pelo Ipea (2011), embora o Protocolo de Gestão Integrada de Serviços, Benefícios e Transferências de Renda no Âmbito do Suas, aprovado pela Resolução no 07/2009 da Comissão Intergestores Tripartite (CIT), "busque fortalecer o Suas como um sistema que organiza, no território nacional, os serviços e os benefícios da assistência social, há distintas autonomias na gestão dos dois 
instrumentos em discussão que precisam ser coordenadas para efetivação de uma gestão mais integrada" (INSTITUTO DE PESQUISA ECONÔMICA APLICADA, 2011, p. 58). Tal situação ainda configura uma lacuna na oferta e operação dos benefícios monetários e serviços socioassistenciais que têm como objetivo a unicidade sistêmica.

3) Maior envolvimento dos estados: na divisão federativa de responsabilidades e esforços para a consolidação do Suas, é evidente o papel preponderante do Governo Federal na regulação e coordenação das relações intergovernamentais e o progressivo comprometimento dos municípios com a implementação do Suas. "Desde 2005, quando surge o sistema, houve grande adesão dos municípios, por meio do processo de habilitação a um dos níveis de gestão do Suas" (INSTITUTO DE PESQUISA ECONÔMICA APLICADA, 2011, p. 61). O mesmo não é verificado em relação aos estados, cuja atuação tem sido marcada pela ausência e irregularidade.

Tal ausência se materializa no apoio técnico insuficiente aos municípios, na omissão de muitos estados na oferta de serviços regionalizados e ainda na irregularidade do cofinanciamento dos serviços socioassistenciais. Em alguns estados, não há cofinanciamento para estes serviços; em outros, quando há, não ocorre via transferências diretas e regulares (fundo a fundo) (INSTITUTO DE PESQUISA ECONÔMICA APLICADA, 2011, p. 80).

A indefinição no papel do estado se torna uma questão de maior relevância quando se observa que a atuação desse faz diferença nos resultados alcançados pelos municípios. Conforme argumentam Palotti e Costa (2011), partindo de estudo sobre a habilitação ao Suas e a implementação dos Cras em municípios do Estado de Minas Gerais, quando ocorre a cooperação do governo estadual, por meio de apoio técnico, financeiro ou estrutural aos municípios, observam-se maiores avanços na implementação da política de assistência social.

4) Melhoria na gestão municipal: embora a esfera municipal constitua-se como o principal ente executor dos serviços, os municípios têm apresentado padrões heterogêneos e muitas vezes inadequados na gestão da política de assistência social. Há problemas na aplicação dos recursos, muitos não conseguem executar as ações planejadas e os recursos disponibilizados não são gastos em ações necessárias de assistência social (INSTITUTO de PesquisA EConôMICA APLICAdA, 2012).

Há também dificuldades apresentadas na relação entre o poder público e as instituições privadas, seja pela manutenção da tradicional orientação clientelística e filantrópica que rege essas relações e a prestação de serviços aos cidadãos, seja porque falta capacidade aos municípios para coordenar as instituições parceiras na direção das normas federais. A carência de profissionais qualificados é outro entrave à política no âmbito local, e isso é verdade para as entidades públicas estatais e 
não estatais. A NOB-RH buscou regulamentar a gestão do trabalho no âmbito do Suas, enfatizando a qualificação, a "desprecarização" dos vínculos profissionais e a educação permanente dos trabalhadores. No entanto, há dificuldade na implementação dos percentuais mínimos estabelecidos de pessoal concursado nas equipes que executam os serviços de proteção social básica e especial nos Cras e Creas, denominadas "equipes de referência". E parte das dificuldades reside na impossibilidade de aplicação dos recursos financeiros federais para pagamento de concursados.

5) Gestão participativa e deliberativa: apesar dos avanços, a inovação da participação da sociedade civil na formulação e implementação da política nacional de assistência social carece de aperfeiçoamento. Os conselhos e conferências de assistência social constituem-se como inovações institucionais que contribuem para a democratização do planejamento público, incluindo a deliberação do orçamento da política para a assistência social, ampliam e aprimoram o espaço democrático entre a sociedade e o Estado e conferem maior transparência e controle às ações públicas da área. No entanto, é preciso consolidar esses espaços deliberativos, delimitando melhor seus campos de atuação, o que evitaria, por exemplo, a concorrência com os espaços de coordenação federativa (CIB e CIT) na deliberação acerca do financiamento da política de assistência social. Também é preciso avançar a gestão deliberativa no planejamento e implementação das políticas, no monitoramento e na avaliação dos resultados alcançados.

\section{Considerações finais}

A assistência social, pós-constituição de 1988, avançou significativamente no sentido de sua consolidação como política pública. Ganhou maior densidade legal, institucional e ampliou a cobertura das ações socioassistenciais para a população em situação de vulnerabilidade social e violação de direitos (INSTITUTO DE PESQUISA ECONÔMICA APLICADA, 2011). No entanto, a construção do Suas é um processo em curso, resultado de normatizações e pactuações entre os entes governamentais e outros atores da política, assim como da implementação das decisões. Nesse processo, são necessários contínuos esforços de coordenação e cooperação federativa para a efetivação de uma gestão mais integrada do Suas como um sistema que organiza, em todo o território, os serviços e benefícios socioassistenciais.

A coordenação federativa em curso na política de assistência social, marcada pela concentração de autoridade no Executivo nacional, é exemplar de um movimento mais geral de recentralização de competências e recursos financeiros na União, vigente principalmente a partir de 1994. Segundo Arretche (2009), tal recentralização pode ser explicada por características institucionais do federalismo 
brasileiro desenhadas na Constituição de 1988. A Constituição confere alta capacidade de iniciar legislação ao governo central e baixo poder de veto aos governos subnacionais, o que resulta em alto grau de sucesso do governo central em aprovar legislação de seu interesse, mesmo quando essa legislação tem impacto direto nos entes subnacionais, limitando sua autonomia.

Sob o prisma da assistência social, a recentralização possibilitou ampla legislação nacional e recursos financeiros à União para induzir comportamentos subnacionais, com destaque para os municípios, o que resultou em uma política mais coordenada federativamente. Dessa forma, a partir de meados dos anos 1990, observam-se avanços na assistência social, com perspectiva de ruptura de padrões históricos de descontinuidade, fragmentação, duplicidade, privatismo e clientelismo. Mas ainda é desafiadora a consolidação do Sistema Único de Assistência Social, o que envolve a superação de alguns desafios atuais, entre eles um maior envolvimento e participação dos entes subnacionais, com destaque para os estados, e da sociedade civil na formulação e implementação da política. Mais desafiadora ainda é a integração da assistência social com as políticas de previdência e saúde, tal qual preconizado na concepção constitucional de seguridade social.

Os desafios apresentados para a política de assistência social brasileira remetem à necessidade de mais pesquisas e trabalhos na área. Na atualidade, são numerosos os trabalhos acadêmicos sobre a assistência social brasileira, sendo que a maioria deles apresenta as mudanças mais recentes operadas na política, se dedica aos benefícios e programas federais (BPC, Bolsa Família etc.) ou são estudos de experiências ocorridas nos municípios. Escassos são os trabalhos que buscam entender a política de assistência social a partir da atuação e relações que os entes federados estabelecem entre si e com as instituições privadas. Há trabalhos sobre experiências subnacionais, mas com pouca discussão sobre as relações intergovernamentais. Dessa forma, conclui-se que há amplo espaço para pesquisas e estudos que exponham mais e melhor o federalismo como uma variável central para a compreensão da política de assistência social, sobretudo em seu modelo atual de sistema único nacional. 


\section{Referências bibliográficas}

ABRUCIO, Fernando L. A coordenação federativa no Brasil: a experiência do período FHC e os desafios do Governo Lula. Revista de Sociologia e Política, n. 24, p. 41-67, 2005.

ALMEIDA, Maria Hermínia Tavares de. Recentralizando a federação? Revista de Sociologia e Política, n. 24, p. 29-40, 2005.

ARRetCHe, Marta. Estado Federativo e políticas sociais. Rio de Janeiro: Revan, 2000. A centralização no Estado Federativo brasileiro. Tese (Livre-docência). Departamento de Ciência Política, Universidade de São Paulo, 2007.

Continuidades e descontinuidades da Federação brasileira: de como 1988 facilitou 1995. Dados, Rio de Janeiro, v. 52, n. 2, p. 377-423, 2009.

(2010), Federalismo e igualdade territorial: uma contradição em termos? Dados, Rio de Janeiro, v. 53, n. 3, p. 587-620, 2010.

BERCovicl, Gilberto. Federalismo e descentralização na Constituição de 1988. In: Bercovicl, G. Dilemas do Estado Federal brasileiro. Porto Alegre: Livraria do Advogado, 2004.

BICHIR, Renata M. Mecanismos federais de coordenação de políticas sociais e capacidades institucionais locais: o caso do Programa Bolsa Família. Tese (Doutorado). Instituto de Estudos Sociais e Políticos (IESP), Universidade do Estado do Rio de Janeiro, Rio de Janeiro, 2011.

BRASIL. Constituição da República Federativa do Brasil. Distrito Federal. Brasília, DF, 5 out. 1988.

BRASIL. Decreto no 6.135, de 26 de junho de 2007. Dispõe sobre o Cadastro Único para Programas Sociais do Governo Federal e dá outras providências. Diário Oficial da União, Brasília, DF, 27 jun. 2007. Disponível em: http://www.planalto.gov.br/ ccivil_03/_ato2007-2010/2007/decreto/d6135.htm. Acesso em 06 jun. 15.

CARDoso JR., J. C.; JACcoud, L. Políticas sociais no Brasil: organização, abrangência e tensões da ação estatal. In: JACcoud, Luciana (Org.). Questão social e políticas sociais no Brasil contemporâneo. Brasília: Ipea, 2005. p. 181-260.

Castro, J. A.; Ribeiro, J. A.; Chaves, J. V.; Duarte, B. C.; Simões, H. B. Gasto social e política macroeconômica: trajetórias e tensões no período 1995-2005. Texto para Discussão no 1324. Brasília: Ipea, 2008.

CôRTES, Soraya M. V. Arcabouço histórico-institucional e a conformação de conselhos municipais de políticas públicas. Educar, Curitiba, Editora UFPR, n, 25, p. 143-174, 2005.

CunHA, Eleonora Schettini Martins. Efetividade deliberativa de conselhos de assistência social. Jundiaí: Paco Editorial, 2013.

FAleIRos, Vicente de Paula. Natureza e desenvolvimento das políticas sociais no Brasil. Capacitação em Serviço Social e Política Social, Módulo 3. Brasília: UnB, 2000. instituto Brasileiro de Geografia e Estatística - IBGE. Perfil dos Municípios Brasileiros (Munic 2009). Assistência Social, Rio de Janeiro, 2010. Disponível em: http://www.ibge.gov.br/home/estatistica/economia/perfilmunic/assistencia_ social2009/munic_as2009.pdf. Acesso em 06 jun. 2015. 
Instituto de Pesquisa Econômica Aplicada (IPEA). Assistência Social. Políticas Sociais: acompanhamento e análise, Brasília, n. 19, 2011.

Cofinanciamento e responsabilidade federativa na política de assistência social. Texto para Discussão n. 1724. Brasília: Ipea, 2012.

LıCıO, E. C. Para além da recentralização: os caminhos da coordenação federativa do Programa Bolsa Família (2003-2010). Tese (Doutorado). Instituto de Ciências Humanas - IH. Departamento de Serviço Social. Universidade de Brasília, Brasília, 2012.

Marshall, T. H. Política social. Rio de Janeiro: Zahar Editores, 1967.

MedeIRos, Marcelo A trajetória do Welfare State no Brasil: papel redistributivo das políticas sociais dos anos 1930 aos anos 1990. Texto para Discussão no 852. Brasília: Ipea, 2001.

PALOTTI, Pedro L. M.; COSTA, Bruno L. D. Relações intergovernamentais e descentralização: uma análise da implementação do Suas em Minas Gerais. Revista de Sociologia e Política, Curitiba, v. 19, n. 39, p. 211-235, 2011.

PETERSON, Paul E. The price of federalism. Washington D. C: The Brookings Institution, 1995.

Obinger, H.; Leibfried, S.; CAStles, F. G. (Eds.). Federalism and the Welfare State: new world and European experiences. Cambridge: Cambridge University Press, 2005.

SILVA, Maria Ozanira da Silva et al. Comunidade Solidária: contradições e debilidades. Serviço Social \& Sociedade, São Paulo, Cortez, n. 60, 1999.

TITMUSS, Richard. M. Social policy: an introduction. London: Edited by Brian AbelSmith and Kay Titmuss, 1974.

VAITSMAN, Jeni; ANDRADE, Gabriela Rieveres Borges; FARIAS, Luis Otávio. Proteção social no Brasil: o que mudou na assistência social após a Constituição de 1988. Ciência \& Saúde Coletiva, v. 14, n. 3, p. 731-741, 2009.

YAZBEK, Maria Carmelita. Pobreza no Brasil contemporâneo e formas de seu enfrentamento. Serviço Social \& Sociedade, n. 110, p. 288-322, 2012.

Márcia Miranda Soares

Possui doutorado em Ciência Política pelo Instituto Universitário de Pesquisas do Rio de Janeiro. Atualmente é professora adjunta do Departamento de Ciência Política da Universidade Federal de Minas Gerais (UFMG). Contato: marciamsoares@uol.com.br

Edite da Penha Cunha

Doutoranda e Mestre em Ciência Política pela Universidade Federal de Minas Gerais (UFMG). É pesquisadora do Núcleo de Estudos em Gestão e Políticas Públicas (Publicus) da UFMG além de atuar na coordenação de programas e projetos de extensão universitária.

Contato: edite@ufmg.br 